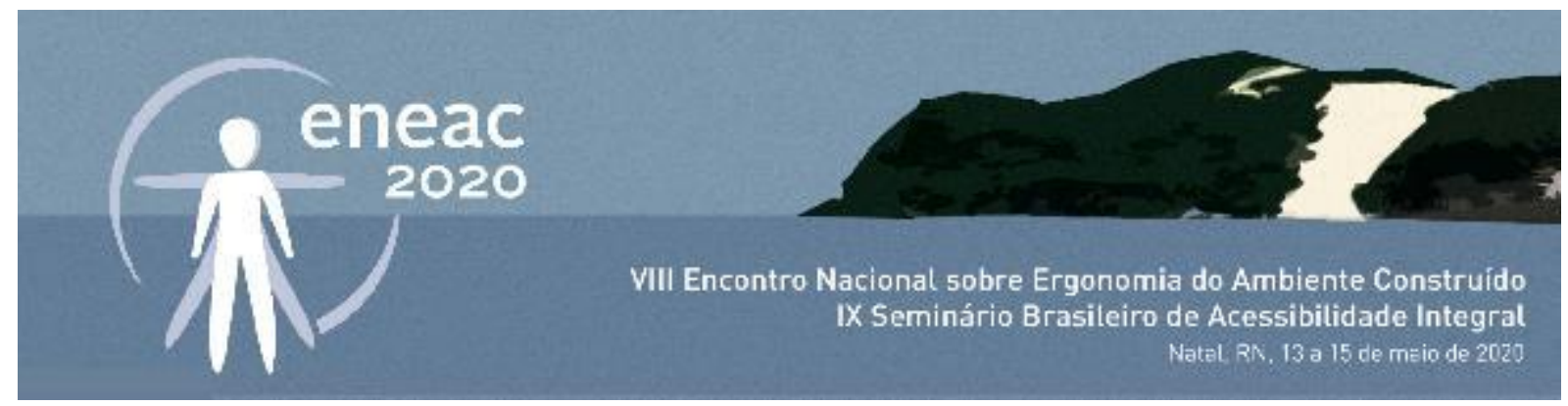

\title{
Ergonomia e programação arquitetônica: reflexões conceituais
}

\section{Ergonomics and architectural programming: conceptual reflections}

\author{
IZABEL FARIAS BATISTA LEITE \\ Doutoranda, Programa de Pós-Graduação em Arquitetura e Urbanismo da Universidade \\ Federal do Rio Grande do Norte - PPGAU/UFRN, izabelfbl@gmail.com
}

HEITOR DE ANDRADE SILVA

Doutor, Professor Permanente do Programa de Pós-Graduação em Arquitetura e Urbanismo da Universidade Federal do Rio Grande do Norte - PPGAU/UFRN, heitor.andrade@ufrn.abea.arq.br

\section{RESUMO}

O projeto de arquitetura centrado no usuário tem se reafirmado nas últimas décadas, sendo, particularmente, evidente na programação arquitetônica, fase analítica do processo, quando problemas e metas são contextualizados e sistematizados. Nesse sentido, observa-se um ponto de convergência com a ergonomia, que se dedica à adequação do espaço às pessoas, evidenciando os condicionantes humanos na tomada de decisões. Nesse sentido, convém refletir: em que medida os princípios da ergonomia são considerados na programação arquitetônica? Este artigo tem, portanto, o objetivo de analisar como a ergonomia está presente e é considerada na fase analítica do processo projetual de edifícios, por meio do estudo de três métodos de programação arquitetônica. $A$ análise terá, como base, uma revisão bibliográfica dos procedimentos desenvolvidos por Peña \& Parshall (2012), Hershberger (2000) e Cherry (1999). Os três autores consideram o fator humano e os princípios ergonômicos na fase inicial do projeto;-as informações obtidas constituem subsídios para as fases subsequentes do projeto.

PALAVRAS-CHAVE: programação arquitetônica, ergonomia, métodos de programação.

\begin{abstract}
The user-centered architecture project has been reaffirmed in recent decades, being particularly evident in architectural programming, the analytical phase of the process, when problems and goals are contextualized and systematized. In this sense, there is a point of convergence with ergonomics, which is dedicated to adapting space to people, highlighting the human constraints in decision making. In this sense, to what extent are principles of ergonomics considered in architectural programming? This article aims to analyze how ergonomics is present in the analytical phase of the building design process in three methods of architectural programming. The analysis will be based on a bibliographic
\end{abstract}




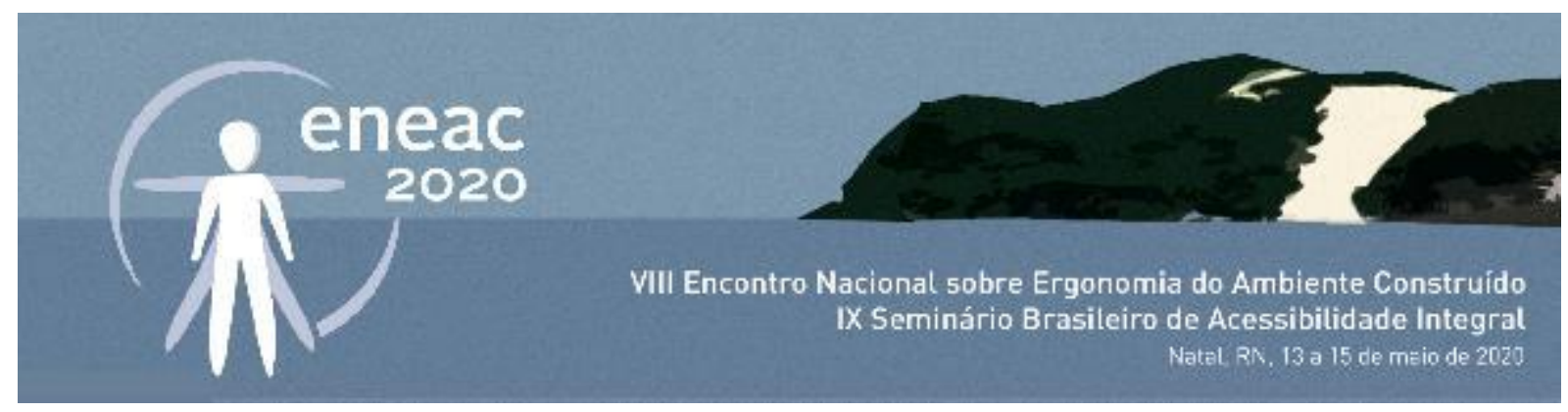

review of the methods developed by Peña \& Parshall (2012), Hershberger (2000) and Cherry (1999). The three authors consider the human factor and ergonomic principles in the initial phase of the project, with the information obtained being subsidies for the subsequent phases of the project.

KEYWORDS: architectural programming, ergonomic, architecture programming methods.

\section{INTRODUÇÃO}

O processo de projeto de arquitetura pode ser definido como um conjunto de atividades intelectuais básicas ordenadas em fases, com características e resultados distintos. Tais fases podem ser compreendidas, segundo Lawson (2011), em: análise, síntese e avaliação. A sequência faz parte de um processo flexível, articulado e interativo. Kowaltowski et al. (2012), em uma interpretação semelhante, embora mais detalhada, identifica seis fases do processo projetual: análise, síntese, previsão, avaliação, decisão e comunicação. Ainda segundo os autores, o projeto arquitetônico, por sua vez, se caracteriza pela decisão de como intervir no espaço, sendo subsidiado por ações precedentes, a exemplo da programação arquitetônica. Os processos de decisão do projetista dividem-se em: programa arquitetônico, projeto, avaliação e decisão, construção e avaliação pósocupação, sendo cada uma, composta por várias atividades.

A elaboração de um projeto, assim como a construção de um edifício são atividades complexas e exigem do arquiteto determinado controle sobre todas as atividades que envolvem o seu processo. A complexidade se dá pelo esforço criativo em propor soluções para os problemas identificados, bem como pela necessidade de conhecer e aplicar diferentes técnicas, materiais, processos construtivos, considerando aspectos econômicos, espaciais e socioculturais.

De acordo com Fernandes (2017), ao longo do processo de concepção, conforme as etapas avançam, menos influência o arquiteto tem sobre o projeto, consequentemente, os custos relativos às modificações aumentam. Logo, infere-se que dedicar um tempo, adequado às etapas iniciais do processo projetual (aqui entendida como a fase analítica), reduz erros e falhas nas etapas posteriores, assim como os custos inerentes às modificações e ajustes, independentemente da escala do projeto.

Portanto, na intenção de aumentar a produtividade e eficiência do arquiteto, faz-se necessário que ele entenda, detalhadamente, os problemas que envolvem o projeto, as necessidades e suas condicionantes. A definição das questões de projeto se insere na etapa analítica do processo projetual, isso porque é nela que ocorre a assimilação dos condicionantes relacionados ao projeto e, consequentemente, são identificados os principais elementos que compõem os problemas. Segundo Jones (1971) a fase de análise é iniciada com uma discussão entre os projetistas sobre as ideias, decorrentes dos primeiros contatos com o problema e é finalizada com a definição de um programa arquitetônico. Alexander (1964) afirma que a análise se refere à etapa de busca do programa mais adequado para um determinado problema.

Compreender o programa arquitetônico como elemento balizador das decisões projetuais, bem como dos resultados das variadas investigações acerca das necessidades do usuário, do orçamento disponível e dos desejos e das intenções dos usuários, permite que o projetista amplie as suas percepções e as possibilidades de soluções no atendimento dos problemas de projeto. Muitas das dificuldades encontradas pelos profissionais, nos processos de decisão, advêm da falta de 


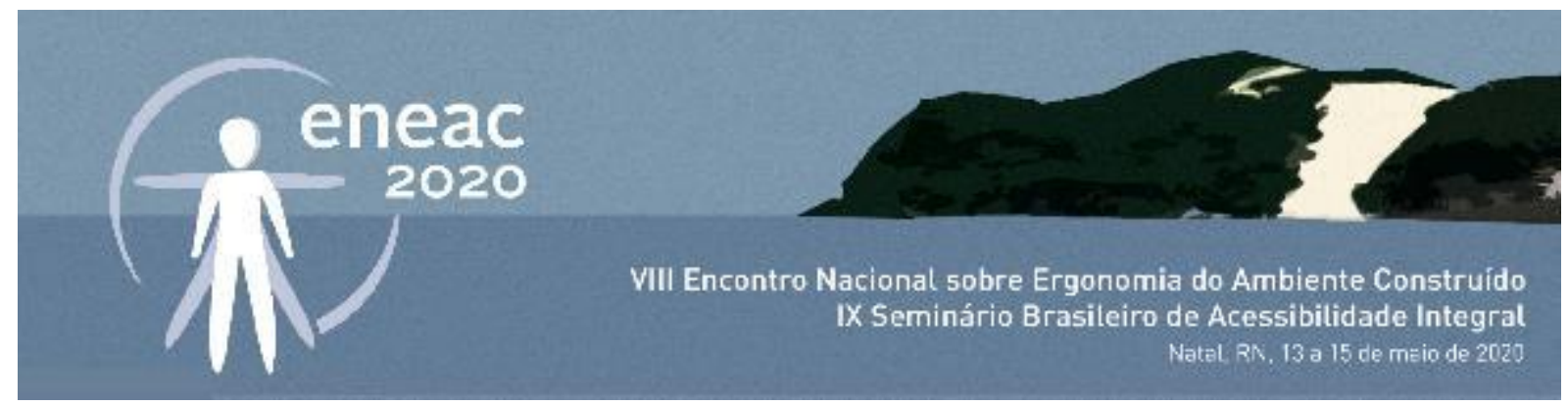

compreensão das várias atividades existentes em determinado espaço e suas inter-relações e dos diversos atores e elementos que as integram.

Em face desse contexto, os princípios da ergonomia podem auxiliar e atuar como fundamento aos arquitetos e favorecer soluções mais adequadas e condizentes com a realidade trabalhada. Para tanto, é importante que tais princípios sejam adotados desde a fase inicial - analítica - do processo projetual, uma vez que é, nesse momento, onde há um maior esforço por parte do projetista em compreender as necessidades, as características e perfis dos usuários envolvidos, o local onde o projeto será implantado, as limitações e possibilidades espaciais, os recursos disponíveis. Tais informações, normalmente, são coletadas com base em um briefing e consultas aos usuários (questionários e entrevistas).

Compreendendo, pois, as relações e correlações entre o processo de projeto, a programação arquitetônica como parte da fase analítica deste e a importância de considerar os princípios ergonômicos desde os primeiros estudos projetuais, o objetivo deste artigo consiste em analisar como a ergonomia está presente na fase analítica do processo projetual de edifícios, em três métodos de programação arquitetônica. Com base em revisão bibliográfica e por meio dos métodos desenvolvidos por três autores - Peña \& Parshall (2012); Hershberger (2000) e Cherry (1999) -, serão observados em que momento a ergonomia é abordada na programação arquitetônica.

Posteriormente, serão expostas as categorias, os procedimentos e as técnicas condizentes com essa análise, visto que ao destacar a importância dos princípios ergonômicos e sua relação com a qualidade arquitetônica e funcional de uma edificação, é possível compreender os impactos em questões relativas, por exemplo, ao dimensionamento e caracterização dos espaços, além dos fluxos e acessos requeridos.

\section{PROGRAMAÇÃO ARQUITETÔNICA E ERGONOMIA: CONSIDERAÇÕES COM ÊNFASE NA FUNÇÃo}

Moreira e Kowaltowski (2016) indicam que um processo de referência, para que projetos com alto padrão de desempenho sejam alcançados, depende, diretamente, do destaque atribuído ao programa arquitetônico. Patterson; Abrahão (2011) complementam:

\footnotetext{
Resultado do processo de programação, o programa arquitetônico apresenta-se como o instrumento balizador das decisões dos projetistas em diferentes etapas do desenho arquitetônico. Entendê-lo como resultante da investigação das necessidades e dos recursos disponíveis, articulados aos objetivos e intenções da organização, permite ampliar as possibilidades de soluções para o atendimento das demandas de projeto (PATTERSON; ABRAHÃO, 2011, p.2).
}

No que se refere a essa etapa, alguns procedimentos já foram investigados e testados, resultando em várias possibilidades de ordenação dos dados. Como exemplo dessas métodos, se destacam os desenvolvidos por Sanoff (2001); a ISSO 9699:1994 e o Problem Seeking, que consiste em estruturar as informações projetuais que um programa deve contemplar e funciona como um checklist para a atividade de programação (PEÑA; PARSHALL, 2012). Moreira e Kowaltowski (2009) apontam que alguns arquitetos também se dedicaram aos estudos de desenvolver um programa arquitetônico - ou programa de necessidades - detalhado como parte do processo projetual, é o caso de Louis Kahn e Richard Neutra. Logo, o uso de métodos é importante no direcionamento do processo de programação e na organização dos conteúdos. 


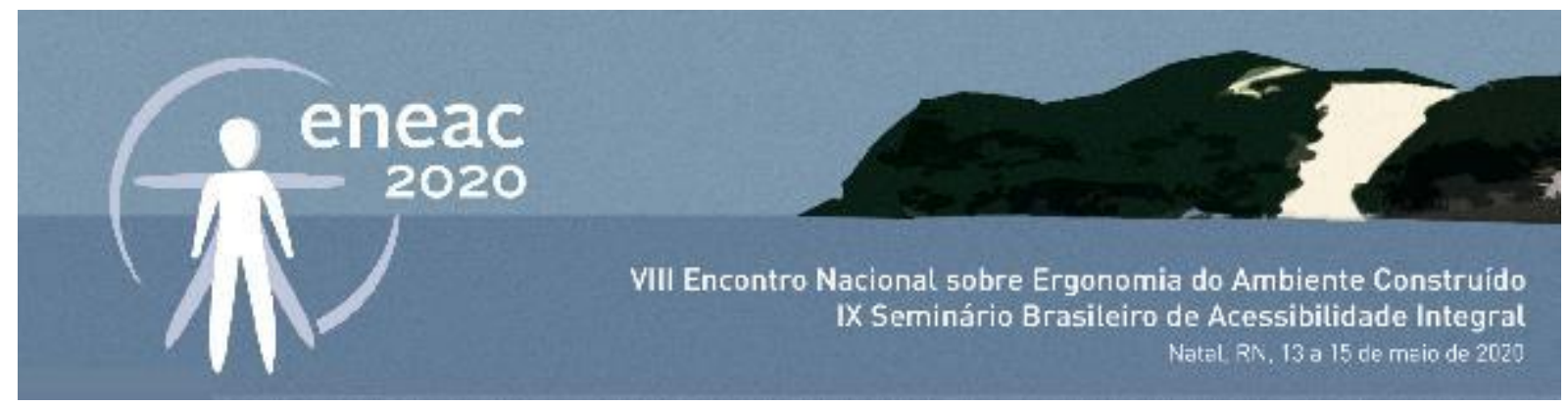

Moreira et al. (2016) afirmam que, inicialmente, o programa é reduzido a uma mera lista de espaços com um quantitativo de áreas que podem definir, principalmente, aspectos relativos aos custos. Em outras palavras, há uma tendência de se reduzir a fase analítica de programação - essencial no processo de projeto - a uma relação de ambientes a que o projeto deverá obedecer, contudo:

Um projeto que se inicia a partir de uma simplificação dessa natureza ignora a riqueza de discussões oferecida pela fase de pré-projeto, nas quais se estabelecem prioridades e se compreende de modo profundo o problema de um projeto. Para evitar essa abordagem pouco científica, as técnicas de programa de necessidades foram criadas. Elas são tão variadas quanto as estruturas que descrevem um contexto. Entretanto, fundamentalmente, os resultados de diferentes programas sobre um mesmo contexto deveriam ser ao menos semelhantes. No ensino de projeto, essas técnicas devem ser aplicadas e testadas: principalmente na pós-graduação o debate da fase analítica do processo deve estimular novas técnicas, ferramentas, métodos e também dinâmicas próprias (MOREIRA et al, 2016, p. 4).

A preocupação, também, é compartilhada por Patterson; Abrahão (2011, p. 4):

A programação arquitetônica é compreendida como o instrumento de conexão entre a expectativa e a concretização do ambiente desejado, que busca formular o problema do projeto, estabelecer as metas e ajustá-los entre si. Para tanto, associa-se a investigação das necessidades dos usuários e dos recursos da organização; e, quanto às metas do projeto, alia-se a investigação das intenções e das suas funções [...]. A associação da programação arquitetônica às etapas do desenho reflete a tendência atual de entender o programa não como o documento detalhado contendo informações técnicas e funcionais, mas como um processo que possibilita a articulação da inter-relação entre os responsáveis pela demanda e os responsáveis técnicos na construção coletiva do projeto (PATTERSON; ABRAHÃO, 2011, p. 4).

A Tabela 1, a seguir, apresenta definições de programação arquitetônica, defendidas por alguns autores preocupados em estudar a temática:

Tabela 1: Definições de programação arquitetônica.

\begin{tabular}{|c|c|}
\hline Definições de Programação Arquitetônica & Autores \\
\hline $\begin{array}{l}\text { "A programação arquitetônica consiste em levantar, compreender e } \\
\text { organizar as informações necessárias para o desenvolvimento do } \\
\text { projeto do edifício. Para isso, o procedimento deve lidar com dados de } \\
\text { diferentes naturezas, obtidos em diversas fontes, mas que devem } \\
\text { estar organizados e documentados a fim de dar apoio ao processo } \\
\text { seguinte, o projeto" }\end{array}$ & $\begin{array}{l}\text { Moreira; } \\
\text { Kowaltowski, } \\
2016, \text { p. } 3\end{array}$ \\
\hline $\begin{array}{l}\text { "A tarefa é reunir os objetivos do cliente em termos de utilidade, } \\
\text { função, qualidade, tempo e custo e definir o desempenho exigido. } \\
\text { Talvez seja sensato distinguir entre necessidades, as quais tem de ser } \\
\text { satisfeitas obrigatoriamente, e desejos, menos imperativos". }\end{array}$ & $\begin{array}{l}\text { Voordt, } 2013, \\
\text { p. } 74 .\end{array}$ \\
\hline $\begin{array}{c}\text { "Bons edifícios não acontecem simplesmente. Eles são planejados } \\
\text { para ter uma boa aparência e funcionar adequadamente [...]. } \\
\text { Programar os requisitos do projeto de um edifício é a primeira tarefa } \\
\text { do arquiteto, se não a mais importante" } \\
\text { "[...] a programação é a investigação do problema, o projeto é a } \\
\text { solução do problema" }\end{array}$ & $\begin{array}{l}\text { Peña; Parshall, } \\
2012 \text {, p. } 12,15 .\end{array}$ \\
\hline $\begin{array}{c}\text { "A programação é o estágio de definição do projeto - o tempo de } \\
\text { descobrir a natureza do problema de projeto mais do que a natureza } \\
\text { da solução do projeto" }\end{array}$ & $\begin{array}{l}\text { Hershberger, } \\
2000, \text { p. } 1 .\end{array}$ \\
\hline $\begin{array}{c}\text { "Programação arquitetônica é a investigação e o processo de decisão } \\
\text { que define o problema a ser solucionado pelo projeto" }\end{array}$ & $\begin{array}{l}\text { Cherry, } 1999, \\
\text { p. } 3 .\end{array}$ \\
\hline
\end{tabular}




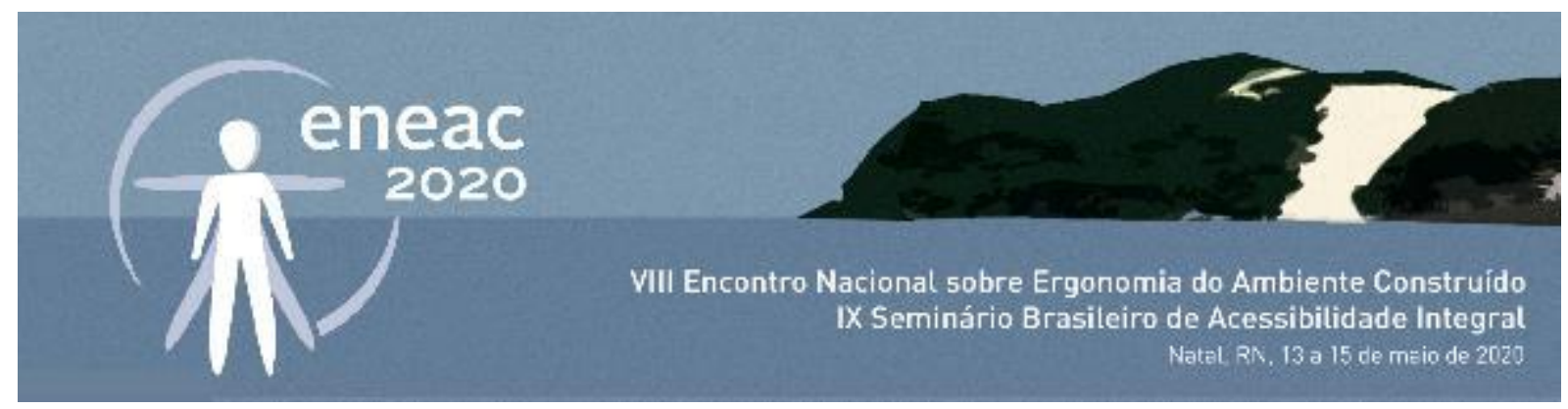

Em face das conceituações expostas acima, pode-se inferir que a programação arquitetônica constitui um processo que tem como objetivo, principalmente, formular e contextualizar o(s) problema(s) de projeto, bem como estabelecer as metas pretendidas no estudo projetual e ajustá-los entre si. O pensamento é compartilhado por Kowaltowski et al. (2011), ao afirmarem que o processo de projeto varia em função, principalmente, da natureza do problema de projeto, do perfil do projetista e das necessidades dos clientes/usuários. Ainda segundo os autores, o processo é mal estruturado porque a maioria dos problemas é mal definida:

\footnotetext{
[...] os fins e os meios das soluções são desconhecidos e externos ao problema, pelo menos no seu conjunto. Embora as características do problema (como tempo, esforço, requisitos) possam ser claras, grande parte da atividade de resolução do problema se dá por definições e redefinições pouco explícitas. Na impossibilidade de descrever os passos que irão levar a uma solução bem-sucedida do problema de projeto, os arquitetos criam soluções e, então, verificam se estas satisfazem as condições colocadas pelo problema (KOWALTOWSKI et al, 2011, p.81)
}

A definição dos problemas de projeto - essencial para que a solução final proposta configure como adequada - também se insere na etapa analítica do processo projetual, isso porque é, nela, onde ocorre a assimilação dos condicionantes relacionados ao projeto, consequentemente, são identificados os principais elementos que compõem o(s) problema(s).

Importa ressaltar que, estruturalmente, o programa - resultado do processo de programação configura um sistema de dados organizados para atender ao processo de projeto e, também, compreender as relações funcionais envolvidas entre o contexto e o espaço físico edificado ou projetado. Logo, as problemáticas expostas pelo programa também são colocadas em termos funcionais. Convém explanar que o programa arquitetônico, como primeiro passo, deve se dedicar à descrição da situação ou dos aspectos gerais da forma, evitando sugestões ou imposição de soluções, uma vez que o usuário é um elemento ativo do contexto, consequentemente, deve ser observado, ouvido para que as necessidades sejam cumpridas mediante uma forma.

Em face do exposto, é necessário entender o que, de fato, seriam esses aspectos funcionais resultantes da etapa de programação e sintetizados em um programa de necessidades, zoneamento e pré-dimensionamento. $\mathrm{O}$ termo função, conforme explanado nos dicionários, é definido como um "tipo especial de atividade" ou "modo de ação". Hillier e Leaman (1976, apud Voordt, 2013) definem quatro funções principais de um edifício: organização das atividades; ajuste ao clima; função simbólica e função econômica, sendo as duas primeiras resumidas a funções de utilidade, e as duas últimas, a funções culturais.

A qualidade funcional, por sua vez, se dá à medida que a edificação e os meios de construção utilizados favorecem ou permitem um grau considerado adequado de apoio à função de utilidade ou as atividades previstas e desejadas. Em outras palavras, a qualidade supracitada deve ser compreendida como respostas adequadas às questões de eficiência e usabilidade prática, considerando os recursos disponíveis.

Respaldado em um panorama mais amplo, a qualidade arquitetônica, segundo Voordt (2013), corresponde à junção da função, forma e técnica e em que medida essa síntese permite a elaboração de um edifício original, confortável, eficiente e com uso responsável dos recursos. Para o autor, a função na qualidade arquitetônica dá destaque ao valor de utilidade, ao planejamento dos espaços em metros quadrados e à subdivisão dos mesmos, além das inter-relações espaciais. 


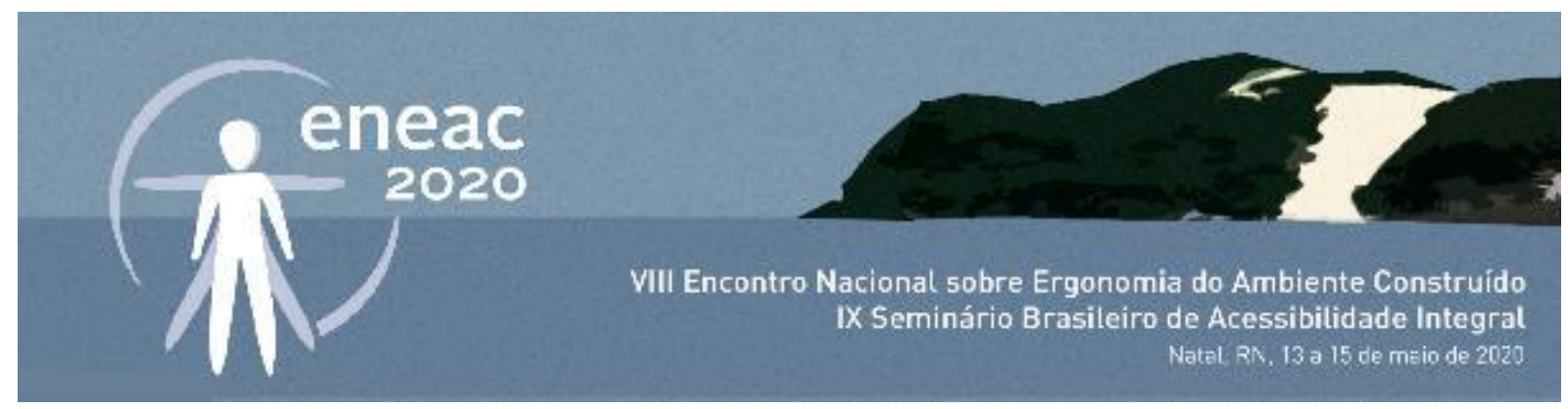

Nesse sentido, considera-se que os princípios ergonômicos se conectam de forma muito próxima com os aspectos funcionais de qualquer que seja a edificação, uma vez que a ergonomia, por si só, configura uma disciplina que estuda a atividade de trabalho com o objetivo de contribuir na concepção de espaços de trabalho adequados e adaptados às características fisiológicas e psicológicas dos indivíduos (Daniellou, 1986). A IEA (International Ergonomics Association) define a ergonomia como uma área do conhecimento que objetiva entender as interações entre os seres humanos e outros elementos de um sistema, a fim de otimizar o bem-estar humano e o desempenho das atividades. Para a associação, a aplicação dos princípios ergonômicos auxilia o projetista a integrar e harmonizar os elementos que interagem com as pessoas e suas respectivas necessidades, habilidades e limitações.

Em face de tais definições, infere-se, pois, que a ergonomia se preocupa, principalmente, com a adequação dos espaços aos seus usuários, assim como a arquitetura. Contudo, ao desenvolver o projeto e, em decorrência de vários fatores (prazo para elaboração, recursos disponíveis, ênfase em outras etapas do processo projetual, etc.), muitas vezes o arquiteto prioriza outros aspectos em detrimento da ergonomia. Ao considerar os aspectos ergonômicos desde o princípio do processo, aspectos como a ocupação, o leiaute, o dimensionamento, os equipamentos necessários para cada ambiente, entre outros, podem ser revistos e reanalisados, ocasionando mudanças significativas no projeto final, já que esse, certamente, estará mais adequado aos seus usuários. A questão principal é que, tanto a arquitetura, quanto a ergonomia, abordam critérios e fundamentos essenciais, mas uma não pode ser desassociada da outra. As duas devem caminhar juntas ao longo do processo projetual. Patterson (2010) reitera esse pensamento ao afirmar que

$$
\begin{aligned}
& \text { a ergonomia e a arquitetura unem-se pelo planejamento e pela investigação das atividades, } \\
& \text { considerando tanto a visão sistêmica do espaço de trabalho como o processo de concepção } \\
& \text { arquitetônica desse sistema. Por meio da ergonomia, é possível entender as atividades humanas e seus } \\
& \text { requisitos de desenho. Por meio da arquitetura, é possível oferecer os elementos para que as atividades } \\
& \text { se realizem. (PATTERSON, 2010, p.44). }
\end{aligned}
$$

A autora ainda relata que as congruências entre a ergonomia e a arquitetura são inegáveis, mas relacioná-las em um projeto requer reflexão por parte do arquiteto visando compreender as interações dos ambientes, relacionando-as com os requisitos de cada atividade, seja as de caráter mais subjetivo ou objetivo.

Assim, considerando a natureza fundamentalmente analítica da programação arquitetônica, aqui, neste artigo, foram escolhidos os procedimentos adotados por Peña \& Parshall (2012), Hershberger (2000) e Cherry (1999), na intenção de identificar e compreender de que forma os princípios ergonômicos se inserem em tais modelos. A escolha dos três métodos ocorreu mediante a representatividade observada nas pesquisas em livros e artigos, nos quais os mesmos sempre eram os autores ou eram citados como referência em obras relativas à programação arquitetônica. Além disso, considera-se que os procedimentos apresentam semelhanças no que se refere à adoção dos princípios ergonômicos.

\section{A ERGONOMIA E OS MÉTODOS DE PROGRAMAÇÃO ARQUITETÔNICA}

A presença da ergonomia nos métodos de programação pode ser considerada um balizador do seu caráter, pois, na condição de uma variável do processo projetual, amplia o grau de precisão do 


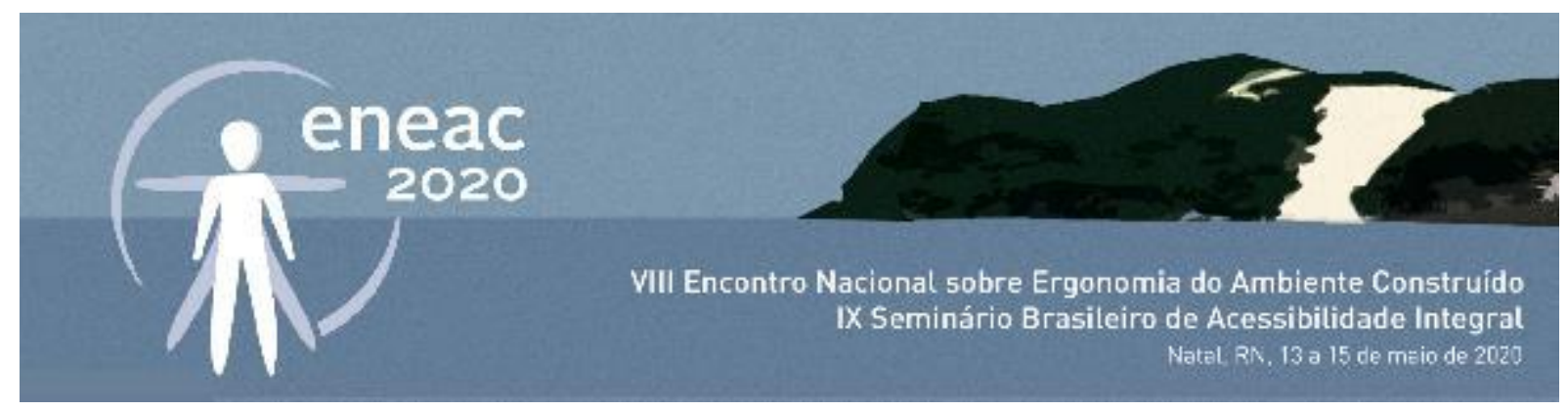

projeto. Em alguma medida, também, configura uma forma de sistematização científica do processo, podendo, inclusive, ser considerado em sua fase inicial. Desse modo, ampliam-se as possibilidades de alcance de padrões de eficiência e qualidade arquitetônica, visto que identifica, compreende e formula o problema de forma mais precisa, detalhada e clara. Os métodos apresentados, neste item, foram escolhidos em decorrência das características analítica e investigativa do problema, bem como das suas aproximações com a ergonomia.

\section{Problem Seeking - Peña \& Parshall (2012)}

Como um método de identificação do problema, o Problem Seeking tenta organizar e priorizar os objetivos de cada projeto ao longo de sua concepção, além de favorecer a relação entre usuário, cliente e arquiteto, na intenção de compreender a natureza de cada problema e suas implicações nas soluções projetuais. Peña \& Parshall (2012) afirmam que o procedimento visa estruturar todas as informações do projeto que o programa arquitetônico deve abranger e serve como um check list para a programação propriamente dita.

Para tanto, os autores definem cinco princípios ou etapas integrantes do processo de programação arquitetônica; são elas: estabelecimento de metas; coleta e análise dos fatos; identificação de conceitos; determinação de necessidades e formulação de problemas. As etapas podem ser obtidas com base nas respostas às seguintes perguntas (PEÑA; PARSHALL, 2012): Metas - O que o cliente quer obter e porquê? Fatos - $\mathrm{O}$ que sabemos? Quais informações temos? Conceitos - Como o cliente pretende alcançar as metas propostas? Necessidades - Quais os recursos e espaços necessários? Qual o nível de qualidade? Problema - Quais são as condicionantes que afetam, significativamente, o projeto? Quais direções o projeto deve seguir?

É importante que os cinco passos e suas respectivas respostas sejam obtidas em ordem, de modo que a última etapa seja definida como resultado. Para que o procedimento seja ainda mais completo, o Problem Seeking ainda estabelece quatro termos de classificação que, posteriormente, deverão ser interligados com os cinco outros aspectos supracitados; são eles: função, forma, economia e tempo. Desse modo, o projetista consegue obter uma análise detalhada e abrangente dos objetivos do projeto; depois, os problemas são definidos e só então é iniciado o desenvolvimento projetual de fato'.

Outro aspecto relevante diz respeito à importância do usuário em todo o processo, com base na coleta de informações por questionários, entrevistas ou conversas em grupo. Nas cinco etapas propostas pelo método (metas, fatos, conceitos, necessidades e problema), desde a primeira existem respostas que só serão obtidas mediante uma conversa com os usuários, para que se compreenda depois como ele pretende alcançar as metas propostas, quais os espaços necessários para que as metas se concretizem e quais aspectos irão afetar o resultado final.

Em um segundo momento, as categorias, mais uma vez, provocam questões que demandam a participação ativa dos usuários. Na função, por exemplo, serão definidas as atividades desenvolvidas no local. Como defini-las se não por intermédio das próprias pessoas que utilizarão o espaço? Além disso, a inserção dos usuários também poderá definir dimensões máximas e mínimas, equipamentos necessários para desenvolvimento das tarefas, acessos e fluxos, etc. Ou seja, trazer o usuário para participar do processo de programação requer a compreensão de que os princípios ergonômicos contribuem para o desenvolvimento projetual, considerando que a ergonomia tem o objetivo 


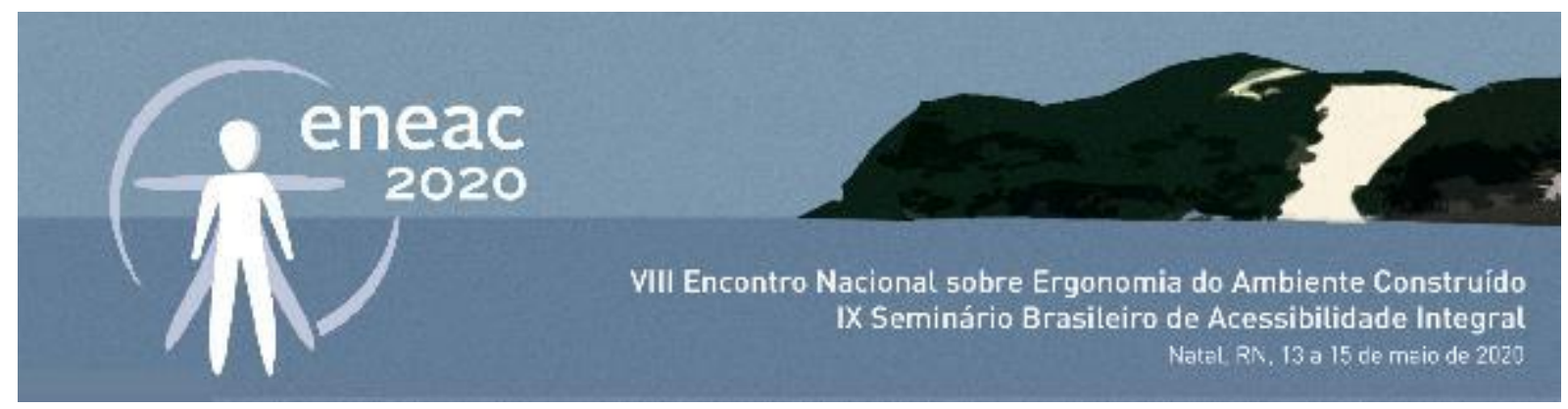

principal de entender as relações entre os seres humanos e os outros elementos, buscando a adequação dos espaços às pessoas que irão utilizá-lo.

Na variável forma, são considerados aspectos de natureza ambiental e humana - tais como, o local, o ambiente físico e psicológico, a qualidade do espaço. Na variável economia, são considerados os recursos disponíveis para execução do espaço edificado. Na variável tempo, são identificados, pelo projetista, elementos do passado (da história) e do futuro. As três categorias mencionadas têm a participação das pessoas, que na condição de usuários contribuem para a compreensão e percepção dos problemas, muitas vezes, inclusive, sugerindo soluções projetuais mais condizentes e legítimas.

Nesse sentido, pode-se inferir que o Problem Seeking, ao atribuir tamanha relevância à participação das pessoas na programação arquitetônica, desde as fases (categorias) iniciais e repercutindo nas fases posteriores, confere ao arquiteto a função de, com base na coleta de dados diretamente com os usuários, considerar os princípios da ergonomia para que a solução projetual final esteja em consonância, especialmente, com as metas, necessidades e problemas apresentados.

\section{Architectural programming and predesign manager - Hershberger (2000)}

O método de Hershberger (2000) propõe uma adaptação do Problem Seeking, resultando em novas categorias de análise (Tabela 2). O procedimento, assim como o citado anteriormente, enfatiza a compreensão e a definição dos problemas; os novos princípios propostos pelo autor visa a elaboração de uma lista dos aspectos geradores das problemáticas de projeto, devendo esta funcionar como ponto de início na investigação e análise das condicionantes que interferem na elaboração do projeto arquitetônico (HERSHBERGER, 2000).

Tabela 2: Programação arquitetônica com base em valores proposta por Hershberger (2000).

\begin{tabular}{|c|c|c|c|c|c|}
\hline VALORES & $\begin{array}{c}\text { DESCRIÇÃO } \\
\text { DOS VALORES } \\
\end{array}$ & METAS & FATOS & NECESSIDADES & IDEIAS \\
\hline Humano & $\begin{array}{l}\text { Funcional, social, físico, } \\
\text { fisiológica e psicológica. }\end{array}$ & & & & \\
\hline Ambiental & $\begin{array}{c}\text { Terreno, condicionantes } \\
\text { naturais, contexto, recursos } \\
\text { e resíduos. }\end{array}$ & & & & \\
\hline Cultural & $\begin{array}{l}\text { Histórico, institucional, } \\
\text { político e legal. }\end{array}$ & & & & \\
\hline Tecnológico & $\begin{array}{c}\text { Materiais, sistemas } \\
\text { construtivos e processos. }\end{array}$ & & & & \\
\hline Temporal & $\begin{array}{c}\text { Crescimento, mudanças, } \\
\text { adaptações e } \\
\text { permanências. }\end{array}$ & & & & \\
\hline Econômico & $\begin{array}{l}\text { Recursos, construção, } \\
\text { operação, manutenção e } \\
\text { energia. }\end{array}$ & & & & \\
\hline Estético & $\begin{array}{c}\text { Forma, espaço, plástica, cor } \\
\text { e significado. }\end{array}$ & & & & \\
\hline Segurança & $\begin{array}{l}\text { Estrutural, fogo, química, } \\
\text { pessoal e criminal. }\end{array}$ & & & & \\
\hline
\end{tabular}




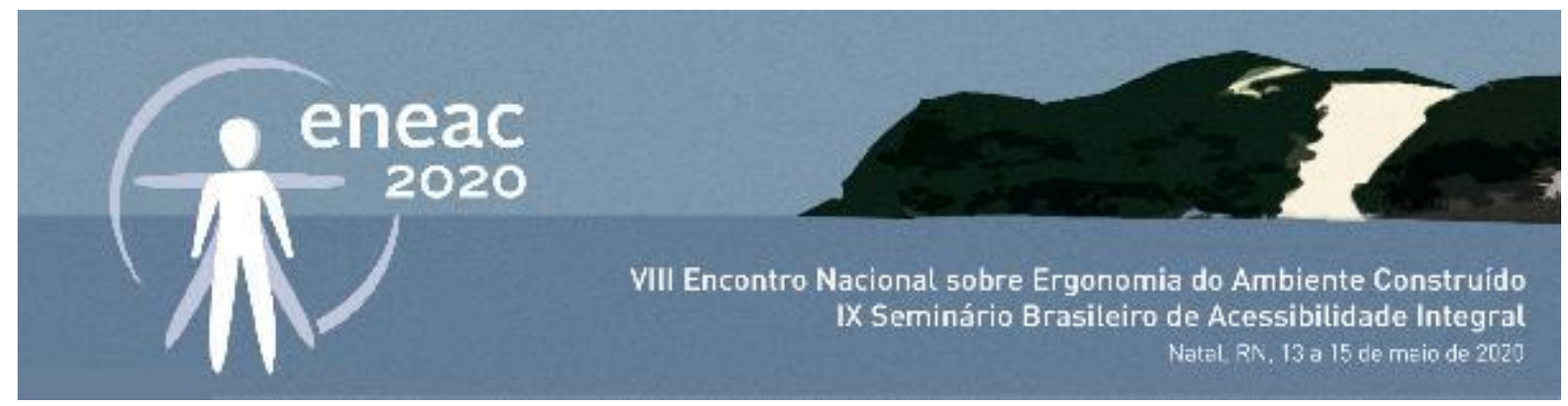

Assim como o Problem Seeking, no método proposto por Hershberger (2000), todas as informações coletadas com base nos valores expostos na Tabela 2 precisam ser sintetizadas, traduzidas e apresentadas em um relatório que deverá ser entregue para todos os envolvidos no processo de projeto. Os dados obtidos devem ser registrados de forma gráfica, com base nos desenhos, diagramas e croquis (KOWALTOWSKI et al, 2012). Ainda sobre esse aspecto, Fernandes (2017) defende:

\begin{abstract}
O formato dessa documentação é flexível e não possui um sistema fixo já definido, devendo se adequar a cada situação. As definições descritas nesse relatório refletem os valores e objetivos dos agentes de projeto e cria uma estrutura que permite ao projetista uma meta a seguir, um caminho mais sólido para alcançar os objetivos propostos e sistematiza as variáveis que devem ser consideradas. (FERNANDES, 2017, p.29).
\end{abstract}

Nesse sentido, é possível verificar que, no método de Hershberger (2000), há um maior esforço, concentração e dedicação do arquiteto na etapa de análise do processo projetual, especialmente na avaliação e definição do problema de projeto, antes de iniciar qualquer estudo espacial.

No que concerne aos princípios ergonômicos, observa-se que, como uma adaptação do procedimento de Peña \& Parshall (2012), continua havendo uma preocupação em fazer com que o usuário participe do processo da programação arquitetônica, consequentemente, atue de maneira ativa na proposição de soluções projetuais. No método de Hershberger (2000) em especial, pode-se constatar que a ergonomia aparece desde o primeiro valor estabelecido pelo autor, como o próprio nome sugere. Posteriormente, as informações coletadas, nesse critério irão subsidiar as subsequentes, principalmente (de forma mais direta) nos valores cultural, temporal, econômico e segurança.

\title{
Programming for design - Cherry (1999)
}

O método estabelecido por Cherry (1999) entende a programação como um processo de pesquisa e de tomada de decisões para definir problemáticas. Para a autora, a programação dá ao projetista uma clara percepção de todo o escopo do projeto e dos critérios que podem favorecer uma boa e adequada solução projetual. Desse modo, a programação ocorre de forma anterior e desassociada, de fato, dos desenhos arquitetônicos (CHERRY, 1999).

O projeto, conforme o método, é dividido em três etapas: masterplan ou plano diretor, estudo preliminar e projeto executivo, sendo, antes de tudo, realizada a programação. É essencial, portanto, que, nesse processo, o projetista tenha um pensamento mais abstrato e não procure dar soluções específicas, uma vez que, primeiro, ele precisa entender o contexto no qual cada problema está inserido. Para tanto, o arquiteto que adota esse método precisa atuar coordenando, mediando e facilitando a programação arquitetônica. De forma complementar, o profissional precisa saber ouvir o usuário para compreender seus objetivos, desejos e aspirações, pois, só assim, ele conseguirá estabelecer os critérios de relação entre os espaços e as pessoas, bem como as atividades que serão realizadas.

As categorias do método idealizado por Cherry (1999) são: fatores humanos, que consistem na função, nas relações sociais e organizacionais, nas projeções e nas atividades desenvolvidas; e, fatores quantitativos, que se referem no dimensionamento dos espaços (obtidos com base em padrões existentes e já reconhecidos ou da antropometria e ergonomia), nos aspectos geográficos ou ambientais (relacionados às características do sítio, condicionantes naturais, topografia). 


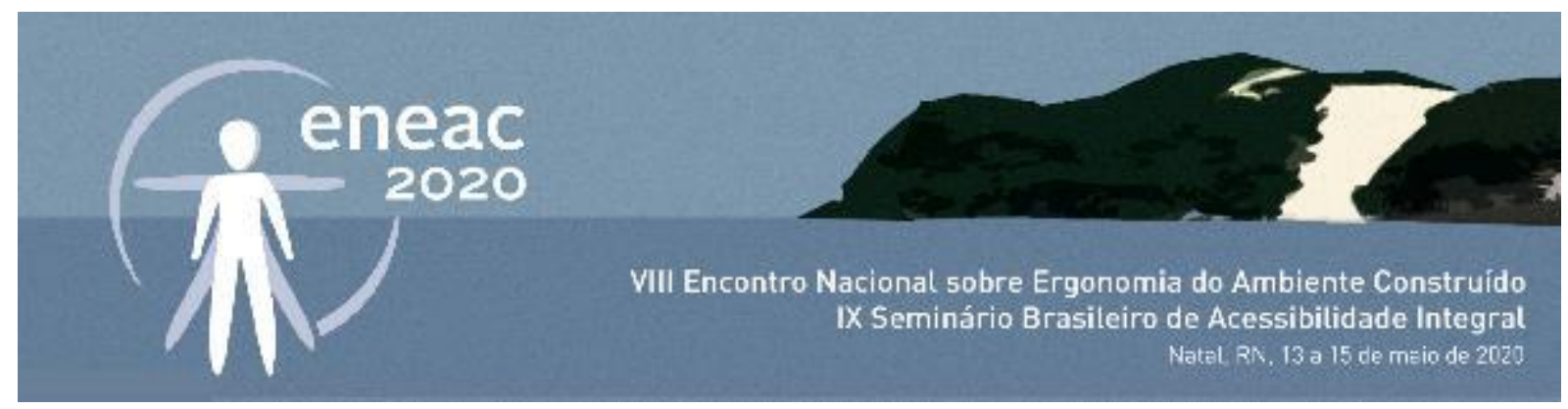

O procedimento de programação arquitetônica envolve seis fases que não precisam, necessariamente, ser executadas na ordem proposta pela autora: 1) pesquisa e compreensão do contexto no qual o projeto está inserido; 2 ) identificação dos objetivos, necessidades e aspirações dos usuários; 3) coleta e análise dos dados; 4) definição das estratégias que serão adotadas para construção do programa arquitetônico; 5) escolha dos requisitos quantitativos e 6) síntese do problema de projeto (CHERRY, 1999).

As informações necessárias para a programação, segundo a autora, são obtidas por meio de questionários; entrevistas individuais ou em grupos; mapas mentais, diagramas, desenhos e fichas (diários) elaboradas pelos próprios usuários; além da técnica de observação dos hábitos e padrões de comportamento no espaço físico.

Nesse sentido, fica explícito que o método proposto por Cherry (1999) considera, também, a importância da participação humana na programação, ao mesmo tempo que estabelece, em sua primeira categoria, denominada "fatores humanos", as diversas variáveis que envolvem o estudo com pessoas e como estas podem influenciar no resultado final - o projeto executivo. Mas a relevância da inserção dos usuários no processo não se limita a essa primeira categoria. Na segunda, "aspectos quantitativos", Cherry relaciona o subjetivo/qualitativo (humano) com o objetivo/quantitativo (dimensões, fatores geográficos e ambientais), reafirmando o que a própria definição de ergonomia assegura - para que os espaços se tornem adequados, é necessário, primeiro, entender quem vai utilizá-los para que exista bem-estar, conforto, maior produtividade nas tarefas desenvolvidas e menores possibilidades de erros e falhas na solução final proposta.

\section{Peña \& Parshall (2012), Hershberger (2000) e Cherry (1999): Semelhanças sob o enfoque da ergonomia}

Conforme afirma Patterson (2010), os métodos de programação arquitetônica se diferem dos demais, pois, além de possuírem uma natureza predominantemente analítica, buscam entender e definir, primeiramente, o contexto, o problema e, só então, iniciar as soluções projetuais propriamente. Essa estratégia de dedicar mais esforço e concentração, na primeira fase do processo de projeto, fornece ao arquiteto maior autonomia e segurança sobre as decisões, além de otimizar o trabalho do profissional, uma vez que ao maturar essas ideias ainda no início, há mais possibilidades de acertos, reduzindo, portanto, o retrabalho.

Outro aspecto que precisa ser considerado é que os métodos de programação, especialmente os aqui abordados, tendem a identificar a singularidade de cada projeto, de cada solução e transformar isso em elementos arquitetônicos que compõem os desenhos. Na programação, o entendimento do contexto existente, seja ele de caráter mais subjetivo ou objetivo, é fundamental para o favorecimento de seu caráter preditivo.

Os métodos de Peña \& Parshall (2012), Hershberger (2000) e Cherry (1999) veem na ergonomia o amparo para compreender o fator humano e como ele interfere em qualquer que seja o projeto. Ademais, os princípios ergonômicos favorecem a interpretação de como as pessoas se relacionam em um espaço, como é a relação delas com os próprios espaços, quais estratégias são adotadas para o cumprimento de determinada tarefa, além das relações interpessoais e os requisitos necessários para o desenvolvimento das atividades. Na Figura 1, é apresentado um quadro resumo em que são expostas as categorias de cada um dos métodos estudados e sua relação com a ergonomia, visando facilitar o entendimento dos mesmos e suas respectivas semelhanças. 


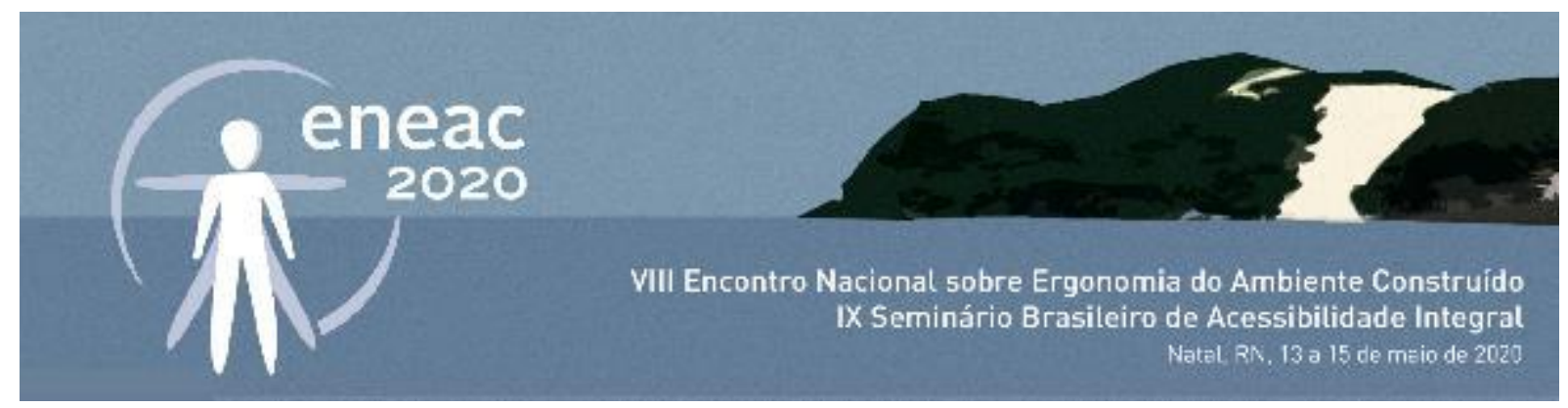

Figura 1: Breve resumo dos métodos abordados e sua relação com a ergonomia.

\begin{tabular}{|c|c|c|}
\hline \multicolumn{3}{|c|}{ MÉTODOS DE PROGRAMAÇÃO ARQUITETÔNICA } \\
\hline Peña \& Parshall (2012) & Hershberger (2000) & Cherry (1999) \\
\hline CATEGORIAS & CATEGORIAS & CATEGORIAS \\
\hline Forma, função, economia e tempo & $\begin{array}{l}\text { Humano, ambiental, cultural, tecnológico, } \\
\text { temporal, econômico, estético, segurança }\end{array}$ & Fatores humanos e fatores quantitativos \\
\hline \multicolumn{3}{|c|}{ INSERÇÃO DOS PRINCÍPIOS DA ERGONOMIA } \\
\hline $\begin{array}{l}\text { Participação dos usuários em todo o } \\
\text { processo, a partir da aplicação de } \\
\text { questionários, entrevistas e conversas em } \\
\text { grupo. }\end{array}$ & $\begin{array}{c}\text { Participação dos usuários em todo o } \\
\text { processo, a partir de registros gráficos } \\
\text { (desenhos, croquis, diagramas, mapas } \\
\text { mentais) }\end{array}$ & $\begin{array}{l}\text { Participação dos usuários em todo o processo. } \\
\text { O arquiteto precisa saber ouvir as pessoas que } \\
\text { utilizarão o espaço para compreender seus } \\
\text { desejos, necessidades e objetivos. }\end{array}$ \\
\hline $\begin{array}{l}\text { Compreensão das funções desejadas e } \\
\text { necessárias; definição de dimensões médias e } \\
\text { equipamentos necessários para realização de } \\
\text { atividades; interpretação das relações } \\
\text { existentes, dos recursos disponíveis e como o } \\
\text { tempo e suas variáveis são vistas pelo } \\
\text { usuário. }\end{array}$ & $\begin{array}{l}\text { Compreensão do valor humano em seus mais } \\
\text { variados aspectos (funcional, social, físico, } \\
\text { fisiológico e psicológico). Interpretação do } \\
\text { valor do tempo para o usuário e quais } \\
\text { recursos disponíveis. Qual a forma e o } \\
\text { significado pretendido. Quais estratégias de } \\
\text { segurança serão adotadas. }\end{array}$ & $\begin{array}{c}\text { Em ambas as categorias, existe uma } \\
\text { preocupação em compreender o fator humano } \\
\text { em sua natureza mais objetiva ou subjetiva } \\
\text { para que a solução projetual se adeque ao } \\
\text { usuário e não o contrário. As duas categorias } \\
\text { se relacionam e resultam nos primeiros } \\
\text { estudos projetuais. }\end{array}$ \\
\hline
\end{tabular}

Fonte: Elaborado pelos autores, 2020.

\section{CONSIDERAÇÕES FINAIS}

Com base na argumentação apresentada e retomando o objetivo dessa reflexão, é válido ressaltar o quanto as duas áreas do conhecimento, aqui expostas, podem se tornar eficazes no desenvolvimento projetual dos edifícios. Para tanto, naturalmente, é necessário que o arquiteto conheça os princípios que norteiam a ergonomia e a programação arquitetônica para que possa aplicá-los da melhor forma possível na intenção de aprimorar o desempenho de suas atividades projetuais cotidianas.

Nesse sentido, convém expor que a retomada da participação das pessoas no processo projetual de edifícios, inclusive, nas etapas mais preliminares pode ser vista em reflexões teóricas mais contemporâneas e em processos considerados colaborativos. A inclusão de variáveis precisas, como a ergonomia, em métodos de programação arquitetônica é um modo de enfrentamento do problema e aperfeiçoamento de práticas projetuais mais eficientes.

Entretanto, mesmo cientes dos benefícios da aplicação das variáveis ergonômicas e dos métodos de programação arquitetônica no desenvolvimento de projetos, ainda é frequente o número de profissionais que não os consideram. Acredita-se que o fato decorre, principalmente, do não conhecimento dos procedimentos específicos propostos pelos métodos de programação e sua consequente relação com os princípios ergonômicos. Isso porque, muitas vezes, a formação acadêmica pouco contempla tais conteúdos, seja nas fases iniciais da graduação ou nas disciplinas de projeto.

Desse modo, é pertinente defender que, se os discentes de arquitetura e urbanismo conhecessem ao longo da graduação, especialmente nos componentes curriculares iniciais, a importância da utilização 


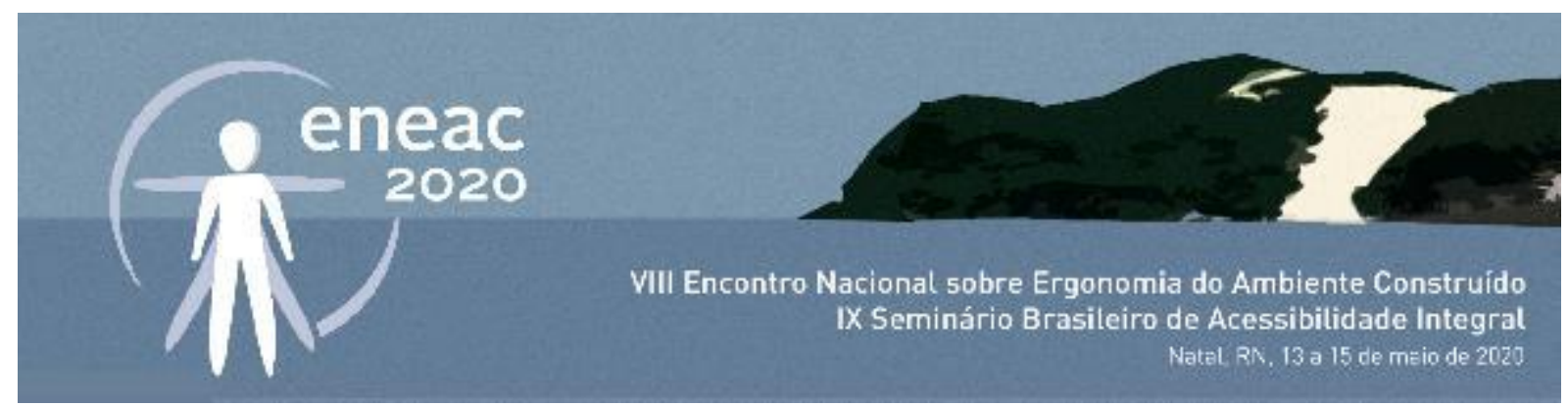

de métodos e procedimentos no desenvolvimento de projetos, com o objetivo de auxiliar na sistematização das informações, passos a serem cumpridos, definição do problema e tomada de decisões e, em um segundo momento os próprios métodos de programação arquitetônica, certamente, teriam mais facilidade de relacioná-los com a ergonomia - disciplina comum e essencial nas graduações em Arquitetura e Urbanismo. Tal postura poderia resultar em processos projetuais, próprios de cada estudante que, provavelmente, seriam, também, utilizados na vida profissional destes anos mais tarde. Esses então arquitetos, por sua vez, poderiam contemplar programação arquitetônica, ergonomia e suas correlações sem grandes dificuldades na elaboração dos seus projetos.

Como perspectivas futuras, é importante observar que, apesar da incorporação de variáveis que considerem o fator humano na fase de compreensão e formulação do problema ser essencial, os métodos de programação arquitetônica devem avançar nesse quesito, considerando a formação dos profissionais, barreiras culturais, tecnologias digitais etc. É indiscutível, contudo, que se trata de um caminho indispensável para se alcançar resultados legítimos.

\section{AGRADECIMENTOS}

Ao Programa de Pós-Graduação em Arquitetura e Urbanismo da Universidade Federal do Rio Grande do Norte - PPGAU/UFRN por possibilitar o desenvolvimento da pesquisa.

\section{REFERÊNCIAS}

ALEXANDER, C. Notes on the synthesis of form. Cambridge: Havard University Press, 1964.

CHERRY, E. Programming for design: From theory to practice. New York: John Wiley and Sons, 1999.

DANIELLOU, F. L'ergonome e lês acteurs de la conception. In: Actes du XXIXème Congrès de la société d'Ergonomie de Langue Française. Enrolles, Paris, 1994, p.27-32.

FERNANDES, R. O. Desen.p.a.c.a. Desenvolvimento de programação arquitetônica de conforto ambiental - uma experiência acadêmica utilizando jogo de tabuleiro. 2017. 218 f. Dissertação (Mestrado) - Programa de Pós-graduação em Arquitetura e Urbanismo, Faculdade de Arquitetura e Urbanismo, Universidade Federal do Rio Grande do Norte, 2017.

HERSHBERGER, R. G. Programming. InThe Architect's handbook of professional practice. 13. Ed. New York: John Wiley and Sons, 2000.

JONES, C. Informe sobre la situación de la metodologia del diseño. In: BROADBENT, G. (Org.). Metodología del diseño arquitectónico. Gustavo Gili, Barcelona, 1971, p. 385-395.

LAWSON, B. Como arquitetos e designers pensam. Oficina de Textos, São Paulo; 4a edição, 2011.

KOWALTOWSKI, D. C. C. K. et al. (Org.). O processo projetual em arquitetura: da teoria à tecnologia. 1. ed. São Paulo: Oficina de Textos, 2011. $504 \mathrm{p}$.

KOWALTOWSKI, D. C. C. K; MOREIRA, D. de C.; DELIBERADOR, M. S. O programa arquitetônico no processo de projeto: discutindo a arquitetura escolar, respeitando o olhar do usuário. Projetos Complexos e os Impactos na Cidade na Paisagem. Rio de Janeiro: Editora UFRJ. p. 160-180. 2012.

MOREIRA, D. C.; KOWALTOWSKI, D. C. C. K.; BELTRAMIN, R. M. G. Dinâmicas que ensinam: a metodologia de projeto no ensino de arquitetura. Gestão e Tecnologia de Projetos, São Carlos, v. 11, n. 1, p. 55-69, jan./jun. 2016.

PATTERSON, C. B.; ABRAHÃO, J. I. A programação arquitetônica sob a ótica da ergonomia: um estudo de caso no setor público. Ambiente construído, Porto Alegre, v. 11, n. 3, p. 177-195, jul./set. 2011. 


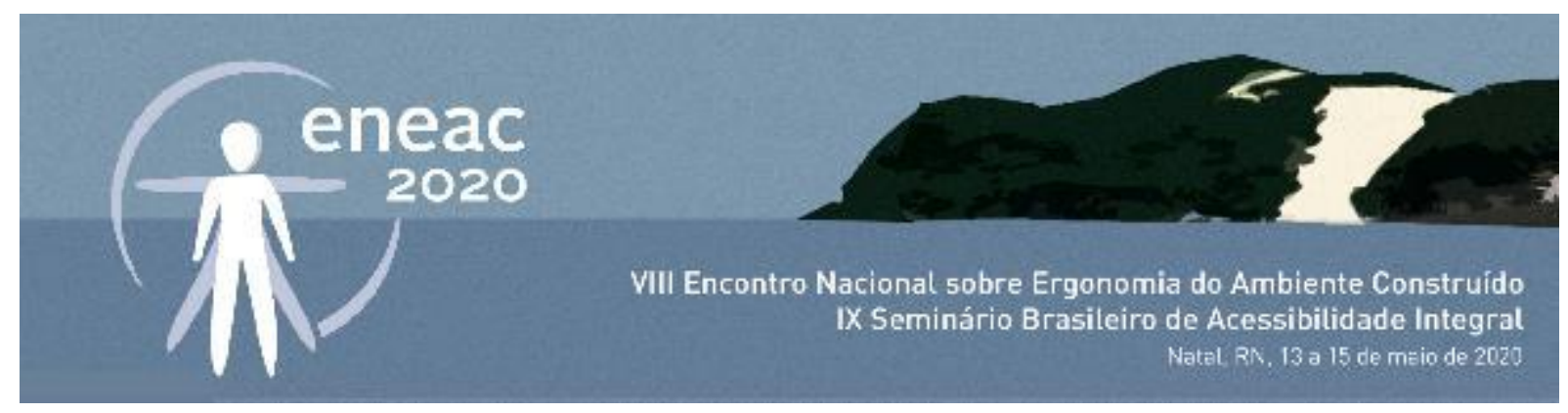

PATTERSON, C. B. Ergonomia e arquitetura: Interfaces na elaboração de programas arquitetônicos. 2010. $229 \mathrm{f}$.

Dissertação (Mestrado) - Programa de Pós-graduação em Psicologia, Faculdade de Psicologia, Universidade de Brasília, 2010.

PEÑA, W. M.; PARSHALL, S. A. Problem Seeking: an architectural programming primer. 5. ed. New York: Wiley, 2012.

VOORDT, T. J. M. Van der. Arquitetura sob o olhar do usuário. São Paulo: Oficina de Textos, 2013. 236 p.

\section{NOTAS}

' É importante ressaltar que existem diferentes modos de compreender o projeto. Para alguns autores, o projeto inclui a fase analítica, para outros, o momento da decisão. No âmbito deste artigo, consideramos a noção de que o projeto é um processo no qual três etapas o compõem: análise, síntese e avaliação. 